\title{
Relationship of cyclosporin and sirolimus blood concentrations regarding the incidence and severity of hyperlipidemia after kidney transplantation
}

G.A. Spinelli, C.R. Felipe, P.G. Machado, R. Garcia, D.E. Casarini, S.R. Moreira, S.I. Park, H. Tedesco-Silva Jr. and J.O. Medina-Pestana
Divisão de Nefrologia, Hospital do Rim e Hipertensão, Universidade Federal de São Paulo, São Paulo, SP, Brasil
Correspondence

H. Tedesco-Silva Jr.

Divisão de Nefrologia

Hospital do Rim e Hipertensão UNIFESP

Rua Borges Lagoa, 960, 11ํandar 04038-002 São Paulo, SP

Brasil

Fax: +55-11-5087-8008

E-mail: heliotedesco@hrim.com.br or gapspinelli@nefro.epm.br

\section{Presented at the 11th Congress of} the European Society for Organ Transplantation, Venice, Italy, September 20-24, 2003.

Publication supported by FAPESP. ...........

Received August 30, 2004 Accepted July 6, 2005

\begin{abstract}
The influence of drug concentrations on the development of persistent posttransplant hyperlipidemia was investigated in 82 patients who received cyclosporin A (CsA) and prednisone plus sirolimus (SRL) (52) or azathioprine (AZA) (30) during the first year after transplantation. Blood levels of CsA and SRL, daily doses of AZA and prednisone, and cholesterol, triglyceride, and glucose concentrations were determined during each visit (pretransplant and 30, 60, 90, 120, 180, and 360 days posttransplant). Persistent hyperlipidemia was defined as one-year average steady-state cholesterol $\left(\mathrm{Cav}_{\mathrm{CHOL}}\right)$ or triglyceride $\left(\mathrm{Cav}_{\mathrm{TG}}\right)$ concentrations above 240 and $200 \mathrm{mg} / \mathrm{dL}$, respectively. Mean cholesterol and triglyceride concentrations increased after transplantation $(\mathrm{P}<0.01)$ and were higher in patients receiving SRL compared to AZA $(\mathrm{P}<0.001)$. Patients receiving SRL showed a significantly higher number of cholesterol ( $>229$ or $>274 \mathrm{mg} / \mathrm{dL}$ ) and triglyceride ( $>198$ or $>282 \mathrm{mg} / \mathrm{dL}$ ) determinations in the upper interquartile ranges. CsA and SRL interquartile ranges correlated with cholesterol concentrations $(\mathrm{P}=0.001)$ whereas only SRL interquartile ranges correlated with triglyceride concentrations $(\mathrm{P}<0.0001)$. Only pretransplant cholesterol concentration $>205 \mathrm{mg} / \mathrm{dL}$ was independently associated with development of persistent hypercholesterolemia $\left(\mathrm{Cav}_{\mathrm{CHOL}}>240 \mathrm{mg} / \mathrm{dL}\right.$, relative risk $(\mathrm{RR})=20$, CI 3.8-104.6, $\mathrm{P}=$ 0.0004 ) whereas pretransplant triglyceride concentration $>150 \mathrm{mg} / \mathrm{dL}$ $(\mathrm{RR}=7.2, \mathrm{CI} 1.6-32.4, \mathrm{P}=0.01)$ or $>211 \mathrm{mg} / \mathrm{dL}(\mathrm{RR}=19.8$, CI 3.6$107.9, \mathrm{P}=0.0006)$ and use of $\mathrm{SRL}(\mathrm{RR}=3, \mathrm{CI} 1.0-8.8, \mathrm{P}=0.0049)$ were independently associated with development of persistent hypertriglyceridemia $\left(\mathrm{Cav}_{\mathrm{TG}}>200 \mathrm{mg} / \mathrm{dL}\right)$. Persistent hypercholesterolemia was more frequent among patients with higher pretransplant cholesterol concentrations and was dependent on both CsA and SRL concentrations. Persistent hypertriglyceridemia was more frequent among patients with higher pretransplant triglyceride concentrations and was dependent on SRL concentrations.
\end{abstract}

Key words - Hyperlipidemia - Cholesterol - Triglyceride - Kidney transplantation - Cyclosporin A - Sirolimus 


\section{Introduction}

Immunosuppression has been associated with hyperlipidemia after kidney transplantation $(1,2)$. While hypertriglyceridemia has been associated with the use of azathioprine (AZA) and steroid $(3,4)$, the combination of cyclosporin A (CsA) and prednisone (PRED) has been predominantly associated with hypercholesterolemia after transplantation (5). The efficacy of the addition of sirolimus (SRL) to the CsA and PRED immunosuppressive regimen for the prevention of acute kidney allograft rejection during the first year after transplantation has been demonstrated in phase III clinical trials $(6,7)$. Compared to other immunosuppressive regimens, the addition of SRL to CsA and PRED immunosuppressive therapy has been associated with increased incidence and severity of hypercholesterolemia and hypertriglyceridemia (8).

The mechanisms by which these drugs interfere with lipid metabolism are different and not completely known. Corticosteroids produce insulin resistance, enhanced activity of acetyl-co-enzyme A carboxylase and free fatty acid synthetase, increased hepatic synthesis and secretion of very low-density lipoprotein (VLDL), down-regulation of low density lipoprotein (LDL) receptor activity, increased activity of 3-hydroxy-3-methylglutaryl co-enzyme A reductase, and inhibition of lipoprotein lipase, resulting in hypercholesterolemia and hypertriglyceridemia $(9,10)$. CsA inhibits bile acid synthesis from cholesterol and transport of cholesterol to the intestines, binds to the LDL receptor, increasing LDL cholesterol levels, reduces post-heparin lipolytic activity, and decreases lipoprotein lipase activity, effects that result in impaired clearance of VLDL and LDL cholesterol $(11,12)$. SRL appears to alter the insulin signaling pathway increasing adipose tissue lipase activity and/or decreasing lipoprotein lipase activity, resulting in increased hepatic synthesis of triglycerides, increased secretion of VLDL, and increased hypertriglyceridemia (13).

All the effects of these drugs appear to be dose or concentration dependent since dose reductions performed routinely during the first posttransplant year are associated with parallel reductions in cholesterol and triglyceride concentrations. Moreover, CsA, SRL and PRED show synergistic pharmacokinetic and pharmacodynamic interactions (14). In animals and humans optimal efficacy with minimal toxicity is achieved with reduced doses of each drug (15). These drugs are all preferentially metabolized by the cytochrome P450 system (16). Therefore, the individual contribution of each drug, regarding dose and/or drug concentrations, to the development of hyperlipidemia after transplantation is not known and is difficult to assess. To address this issue, we selected a kidney transplant population with low pretransplant risk factors associated with hyperlipidemia, which received the same CsAand PRED-based immunosuppressive therapy, plus AZA or SRL, during the first year after transplantation.

\section{Subjects and Methods}

\section{Population}

Between June 10, 1999 and October 31, 2000 we reviewed the charts of 125 transplanted patients who received CsA and PRED immunosuppressive therapy without induction with monoclonal or polyclonal antibodies. As adjunctive therapy 90 patients received SRL and 35 patients received AZA. Inclusion criteria were 13 years of age or more and weight of more than $40 \mathrm{~kg}$. Patients were also required to have total white blood cell count $\geq 4.0 \times 10^{9} / \mathrm{L}$, platelet count $\geq 100.0 \times 10^{9} / \mathrm{L}$, fasting cholesterol $\leq 350$ $\mathrm{mg} / \mathrm{dL}(\leq 9.1 \mathrm{mmol} / \mathrm{L})$ and/or fasting triglycerides $\leq 500 \mathrm{mg} / \mathrm{dL}(\leq 5.65 \mathrm{mmol} / \mathrm{L})$ during a pretransplant screening evaluation. Women of childbearing potential were required to 
have a negative pregnancy test before administration of the study medication and to practice medically approved birth control throughout the study and for 3 months following discontinuation of SRL. Patients were excluded if they had evidence of systemic infection, a history of clinically significant cardiac abnormalities or malignancy within 10 years of enrollment into the study and if they had received treatment with an investigational agent within 4 weeks of administration of SRL. Prophylaxis for Pneumocystis carinii pneumonia and cytomegalovirus infection was mandatory for all patients. The local medical Ethics Committee approved all protocols and the studies were performed in accordance with the Declaration of Helsinki and US Food and Drug Administration guidelines for good clinical practice. All patients signed a written informed consent form after being informed of the nature and details of the studies.

\section{Immunosuppressive treatment and monitoring}

Prior to graft revascularization all patients received $1 \mathrm{~g}$ methylprednisolone. Within $24 \mathrm{~h}$ after transplant surgery, patients received an initial CsA dose of 8 to $10 \mathrm{mg} /$ day twice daily, $0.5 \mathrm{mg} \mathrm{kg}^{-1}$ day $^{-1}$ of PRED (maximum of $30 \mathrm{mg} /$ day), and AZA ( $2 \mathrm{mg}$ $\mathrm{kg}^{-1}$ day $^{-1}$ ) or SRL (a 6-mg loading dose followed by a 2-mg fixed daily dose of SRL, $1 \mathrm{mg} / \mathrm{mL}$; Wyeth-Ayerst Research, Radnor, PA, USA), administered $4 \mathrm{~h}$ after the morning CsA dose. CsA doses were adjusted to keep the whole blood through CsA concentrations between 200 and $400 \mathrm{ng} / \mathrm{mL}$ during the first 4 weeks, 150 to $300 \mathrm{ng} / \mathrm{mL}$ from week 5 to week 12 , and between 100 and 200 $\mathrm{ng} / \mathrm{mL}$ thereafter. To minimize SRL potentiation of the nephrotoxic effects of CsA, after the fourth post-transplant week patients receiving SRL had their CsA doses adjusted to keep blood concentrations within the lower range of the therapeutic window, in contrast to patients receiving AZA who had their CsA doses adjusted to the middle or upper range level.

\section{Study design}

To understand the impact of the exposure to immunosuppressive drugs on lipid and glucose profiles, we performed a retrospective analysis of the influence of blood CsA and SRL concentrations, and daily PRED doses on total serum cholesterol and triglycerides, and on plasma glucose concentrations up to 12 months after transplantation. To assess these relationships, we selected data from patients continuously receiving either SRL or AZA in combination with CsA and PRED up to the end of first post-transplant year. Forty-three patients were excluded from analysis, 10 due to pre-transplant (9 SRL, 1 AZA) and 7 due to post-transplant (5 SRL, 2 AZA) diabetes mellitus; 9 (SRL) due to changes in initial immunosuppressive therapy (anemia (2), graft loss (1), hyperlipidemia (1), lack of efficacy (2), urinary fistula (1), parvovirus (1), and hemolytic uremic syndrome (1)); 10 (SRL) due to early withdrawal PRED; 3 due to graft losses (2 SRL and 1 AZA). Four patients (3 SRL and 1 AZA) died. Therefore, the data of 82 patients, 52 in the SRL group and 30 in the AZA group, were used for analysis. Study visits were performed pretransplant and 30 , $60,90,120,180$, and 360 days after transplantation. During each visit, AZA and PRED doses, blood CsA and SRL levels and cholesterol, triglycerides, and glucose concentrations were determined. The number of patients requiring statins to control hyperlipidemia was also determined.

\section{Bioanalytical methods}

Whole blood CsA concentrations were determined with the AxSYM CsA fluorescence polarization immunoassay kit (Abbott Laboratories, Chicago, IL, USA), according 
to manufacturer directions. Performance was assessed on the basis of a 3-point quality control concentration range of low (70 ng/ $\mathrm{mL}$ ), intermediate (300 $\mathrm{ng} / \mathrm{mL})$, and high $(600 \mathrm{ng} / \mathrm{mL})$ concentrations. Whole blood SRL concentrations were measured using a validated HPLC method (17) and performance was assessed using two quality control concentrations (10 and $50 \mathrm{ng} / \mathrm{mL}$ ). Serum cholesterol and triglyceride concentrations and plasma glucose concentrations were analyzed by an enzymatic and colorimetric method using the COBAS MIRA-plus software (Basel, Switzerland).

\section{Diagnosis and treatment of hyperlipidemia}

The diagnosis of hyperlipidemia was generally made based on a cholesterol concentration above $240 \mathrm{mg} / \mathrm{dL}$. At the time of the diagnosis of hyperlipidemia, patients first received dietary advice and instructions to increase exercise. In case of persistence of hyperlipidemia, treatment with statins (pravastatin, fluvastatin, atorvastatin, and cerivastatin) was introduced. The time of introduction and the duration of treatment, as well as the type and dose of statins were not uniform among patients. All decisions were made at the discretion of the attending physician. The lipid-lowering therapy was interrupted in the presence of any adverse event related to the statins, mostly hepatic and skeletal muscle dysfunction. No patient received fibrates and we did not observe any case of rhabdomyolysis.

\section{Concentration-effect relationships}

Correlations between drug doses or concentrations and cholesterol, triglyceride or glucose concentrations were calculated as follows: 1) mean cholesterol, triglycerides and glucose in patients receiving AZA or SRL, regardless of blood SRL concentrations; 2) fraction of patients receiving SRL or AZA showing increasing cholesterol or triglyceride concentrations (interquartile ranges) and need for statins during the first year after transplantation; 3) correlation between individual blood CsA and SRL concentrations and PRED doses and serum cholesterol and triglyceride concentrations over time; 4) correlations between CsA and SRL concentrations, divided into quartiles, and serum cholesterol and triglyceride concentrations; 5) univariate and multivariate analyses were performed including demographic characteristics, average steady-state drug concentrations (Cav) and statin use to search for independent risk factors associated with the development of persistent posttransplant hyperlipidemia (8). It has been demonstrated in kidney transplant patients that a) CsA concentrations and PRED doses decrease over time; b) the administration of fixed SRL doses produces a time-dependent increase in blood concentrations after transplantation; c) cholesterol and triglyceride concentrations increase after transplantation in patients receiving CsA-based immunosuppressive therapy, reaching a plateau around 3 months posttransplant. These data demonstrate that time is also a confounding variable that may influence individual cholesterol and triglyceride concentrations. Therefore, instead of performing only simple correlations at specific time points between drug concentrations and cholesterol and triglyceride levels we decided to take advantage of a pharmacokinetic approach. CsA, SRL, PRED, cholesterol, and triglyceride concentrations were plotted over time during the first 12 months of transplantation and areas under the curve were measured using the trapezoidal rule. Areas under the curve were calculated using individual values obtained on the occasion of each visit during the first year of transplant and then divided by 360 days to yield mean Cav. We then defined patients as having persistent hypercholesterolemia or hypertriglyceridemia if they showed $\mathrm{Cav}_{\mathrm{CHOL}}$ or $\mathrm{Cav}_{\mathrm{TG}}$ values higher than 240 and $200 \mathrm{mg} / \mathrm{dL}$, respectively. 


\section{Statistical analysis}

Data concerning demographic characteristics and drug or biochemical evaluations were submitted to descriptive analysis using means and standard deviation for continuous variables and proportions for categorical variables. Comparisons between groups were performed by the unpaired two-tailed Student $t$-test and by the chi-square test. A general model for repeated measures was applied, with time posttransplant and treatment groups (AZA or SRL) used as covariates for within- and between-subject variability. Simple and multiple linear regression was used to correlate drug concentrations and cholesterol and triglyceride concentrations. Two-way analysis of variance was used to analyze the influence of different concentration ranges (quartiles) of $\mathrm{CsA}$ and SRL on cholesterol and triglyceride concentrations. Areas under the time-concentration curves during the first year were calculated using WinNonlin software (SCI software, Salt Lake City, UT, USA). Multivariate analysis and logistic regression analysis were performed to identify risk factors for the development of persistent hypercholesterolemia or hypertriglyceridemia. All statistical analyses were performed using SPSS software (SPSS Inc., Chicago, IL, USA).

\section{Results}

\section{Demographic characteristics}

The demographic characteristics of the patient population, shown in Table 1, are representative of our general adult transplant population. Mean age was $35.6 \pm 10.5$ years, mean body mass index (BMI) was 24 $\pm 2.8 \mathrm{~kg} / \mathrm{m}^{2}, 72 \%$ of the patients were males and $66 \%$ were white. The most frequent causes of end-stage renal disease were chronic glomerulonephritis (29\%), hypertension $(21 \%)$ and others $(50 \%)$. This was predominantly a nonsensitized population with a mean panel reactive antibody of 0.93 $\pm 6 \%$ and mean human leukocyte antigen mismatches of $3.6 \pm 1.3$, with a significant difference when comparing patients receiving AZA or SRL $(3.0 \pm 0.5$ vs $4.0 \pm 1.5, \mathrm{P}<$ $0.05)$, respectively. Regarding recognized pretransplant risk factors, there were no significant differences in mean cholesterol, triglyceride or glucose concentrations, in mean time on dialysis or in the percentage of patients with hypertension (Table 1). All patients tested negative for hepatitis $\mathrm{C}$ and $\mathrm{B}$, $86 \%$ were positive for cytomegalovirus. None of the patients was receiving lipidlowering agents before transplantation. Except for a higher mean human leukocyte antigen mismatch, there were no significant differences in any demographic variables between patients receiving SRL or AZA.

Table 1. Demographic characteristics of the transplant population.

\begin{tabular}{|c|c|c|c|}
\hline & Total $(\mathrm{N}=82)$ & $S R L(N=52)$ & $A Z A(N=30)$ \\
\hline Age (years) & $36.0 \pm 10.5$ & $37.0 \pm 11.0$ & $33.0 \pm 10.0$ \\
\hline BMI $\left(\mathrm{kg} / \mathrm{m}^{2}\right)$ & $24.0 \pm 3.0$ & $24.0 \pm 3.5$ & $24.0 \pm 1.0$ \\
\hline \multicolumn{4}{|l|}{ Gender, N (\%) } \\
\hline Male & $59(72)$ & $39(75)$ & $20(67)$ \\
\hline Female & $23(28)$ & $13(25)$ & 10 (33) \\
\hline \multicolumn{4}{|l|}{ Ethnicity, N (\%) } \\
\hline White & $51(62)$ & $33(63)$ & $18(60)$ \\
\hline Black & $15(18)$ & $8(15)$ & $7(23)$ \\
\hline Mulatto & $16(20)$ & $11(22)$ & $5(17)$ \\
\hline \multicolumn{4}{|l|}{ Cause of ESRD, $\mathrm{N}(\%)$} \\
\hline Chronic glomerulonephritis & $24(29)$ & $13(25)$ & $11(37)$ \\
\hline Hypertension & $18(22)$ & $14(27)$ & $4(13)$ \\
\hline Polycystic kidney & $2(2)$ & $2(4)$ & 0 \\
\hline Unknown origin & $3(4)$ & $3(6)$ & 0 \\
\hline Other & $35(43)$ & $20(38)$ & $15(50)$ \\
\hline HLA mismatch* & $3.5 \pm 1.5$ & $4.0 \pm 1.5$ & $3.0 \pm 0.5$ \\
\hline \multicolumn{4}{|l|}{ Pre-transplant risk factors } \\
\hline Cholesterol (mg/dL) & $172.0 \pm 48.5$ & $179.0 \pm 52.0$ & $159.0 \pm 39.0$ \\
\hline Triglycerides (mg/dL) & $174.0 \pm 101.0$ & $185.0 \pm 111.5$ & $157.0 \pm 79.0$ \\
\hline Glycemia (mg/dL) & $90.5 \pm 23.0$ & $94.5 \pm 26.0$ & $83.5 \pm 13.0$ \\
\hline Hypertension (N, \%) & $69(84)$ & $47(90)$ & $22(73)$ \\
\hline Dialysis time (months) & $20.0 \pm 17.0$ & $22.0 \pm 19.0$ & $16.0 \pm 12.0$ \\
\hline
\end{tabular}




\section{Immunosuppressive regimens}

From day $30(442 \pm 100$ vs $360 \pm 99 \mathrm{mg} /$ day, $\mathrm{P}=0.001)$ to day $360(263 \pm 74$ vs 146 $\pm 59 \mathrm{mg} /$ day, $\mathrm{P}<0.001$ ), patients treated with SRL were receiving significantly less CsA to minimize potential drug interaction as described in the Methods section. These differences ranged from $19 \%$ at day 30 to $44 \%$ at day 360 . This resulted in significantly lower mean CsA concentrations from day 60 to day 360 in patients receiving SRL compared to AZA (Table 2). As a result of a faster taper in PRED doses, patients receiving SRL were receiving lower mean PRED doses at day 90 compared to patients receiving AZA. Nevertheless, there were no significant differences in mean PRED doses at the end of 6 or 12 months after transplantation (Table 2). Although patients were receiving fixed 2-mg daily doses of SRL, high inter- and intraindividual variability in blood SRL concentrations were observed. Mean blood SRL concentrations increased from $7.7 \pm 3.7 \mathrm{ng} / \mathrm{mL}$ at day 30 to $10.2 \pm 7.4 \mathrm{ng} /$ $\mathrm{mL}$ at day $120(\mathrm{P}=0.057)$ with no further increase until day 360 , suggesting achievement of pharmacokinetic stability. There were no significant temporal differences in mean AZA doses from day $30(130 \pm 32.4$

Table 2. Comparison of the mean immunosuppressive drug doses and concentrations in patients receiving sirolimus and azathioprine.

\begin{tabular}{|c|c|c|c|c|c|c|}
\hline \multirow[t]{2}{*}{ Days after transplant } & \multicolumn{3}{|c|}{ Sirolimus $(N=52)$} & \multicolumn{3}{|c|}{ Azathioprine $(\mathrm{N}=30)$} \\
\hline & $\begin{array}{c}\mathrm{CsA} \\
(\mathrm{ng} / \mathrm{mL})\end{array}$ & $\begin{array}{l}\text { PRED } \\
\text { (mg/day) }\end{array}$ & $\begin{array}{c}\mathrm{SRL} \\
(\mathrm{ng} / \mathrm{mL})\end{array}$ & $\begin{array}{c}\text { CsA } \\
(\mathrm{ng} / \mathrm{mL})\end{array}$ & $\begin{array}{l}\text { PRED } \\
\text { (mg/day) }\end{array}$ & $\begin{array}{c}\text { AZA } \\
\text { (mg/day) }\end{array}$ \\
\hline 30 & $286.7 \pm 110.2$ & $23.5 \pm 4.7$ & $7.7 \pm 3.7$ & $324.6 \pm 96.5$ & $25.7 \pm 5.2$ & $130.0 \pm 32.4$ \\
\hline 60 & $166.0 \pm 77.5^{a}$ & $14.3 \pm 4.7$ & $8.1 \pm 4.4$ & $216.6 \pm 78$ & $16.0 \pm 4.2$ & $124.2 \pm 33.1$ \\
\hline 90 & $155.2 \pm 87.1^{a}$ & $11.1 \pm 2.3$ & $9.1 \pm 5.1$ & $196.0 \pm 75.1$ & $14.3 \pm 4.1^{b}$ & $124.2 \pm 33.1$ \\
\hline 120 & $131.4 \pm 52.0^{b}$ & $10.6 \pm 1.9$ & $10.2 \pm 7.4$ & $182.6 \pm 66.6$ & $10.0 \pm 1.9$ & $119.2 \pm 38.1$ \\
\hline 180 & $131.0 \pm 57.4^{b}$ & $10.2 \pm 2.4$ & $7.4 \pm 3.9$ & $162.8 \pm 62.6$ & $9.7 \pm 1.3$ & $122.5 \pm 36.2$ \\
\hline 360 & $102.1 \pm 70.8^{a}$ & $9.2 \pm 4.7$ & $10.7 \pm 7.0$ & $187.8 \pm 76.5$ & $9.8 \pm 2.0$ & $118.5 \pm 32.2$ \\
\hline
\end{tabular}

CsA = cyclosporin A; PRED = prednisone; $\mathrm{SRL}=$ sirolimus; $\mathrm{AZA}=$ azathioprine.

aP $<0.05$ and $\mathrm{bP}<0.001$ for CsA concentrations or daily PRED doses of patients receiving sirolimus compared to those of patients receiving azathioprine (unpaired Student $t$-test).

Table 3. Cholesterol, triglyceride and glucose concentrations during the first year of transplant in patients receiving sirolimus or azathioprine in combination with cyclosporine and prednisone.

\begin{tabular}{|c|c|c|c|c|c|c|c|c|c|}
\hline \multirow[t]{2}{*}{ Days after transplant } & \multicolumn{3}{|c|}{ Cholesterol (mg/dL) } & \multicolumn{3}{|c|}{ Triglycerides (mg/dL) } & \multicolumn{3}{|c|}{ Glucose (mg/dL) } \\
\hline & Total $\left.\right|^{a}$ & SRL & AZA & Totala & SRL & AZA & Total & SRL & AZA \\
\hline 0 & $172 \pm 49$ & $180 \pm 52$ & $159 \pm 39$ & $174 \pm 101$ & $185 \pm 112$ & $157 \pm 79$ & $91 \pm 23$ & $95 \pm 26$ & $84 \pm 13^{b}$ \\
\hline 30 & $279 \pm 91$ & $299 \pm 102$ & $244 \pm 57^{b}$ & $217 \pm 129$ & $236 \pm 134$ & $186 \pm 113$ & $92 \pm 15$ & $92 \pm 13$ & $93 \pm 18$ \\
\hline 60 & $259 \pm 71$ & $281 \pm 71$ & $220 \pm 52^{b}$ & $247 \pm 149$ & $271 \pm 170$ & $206 \pm 90^{b}$ & $95 \pm 16$ & $97 \pm 17$ & $91 \pm 15$ \\
\hline 90 & $249 \pm 59$ & $265 \pm 63$ & $222 \pm 37^{b}$ & $247 \pm 162$ & $279 \pm 187$ & $191 \pm 80^{b}$ & $98 \pm 18$ & $101 \pm 20$ & $94 \pm 14$ \\
\hline 120 & $240 \pm 56$ & $251 \pm 64$ & $222 \pm 33^{b}$ & $253 \pm 167$ & $283 \pm 193$ & $198 \pm 86^{b}$ & $98 \pm 15$ & $100 \pm 17$ & $94 \pm 11$ \\
\hline 180 & $235 \pm 62$ & $247 \pm 69$ & $216 \pm 41^{b}$ & $238 \pm 125$ & $265 \pm 140$ & $192 \pm 77^{b}$ & $95 \pm 19$ & $99 \pm 20$ & $90 \pm 14^{b}$ \\
\hline 360 & $236 \pm 62$ & $252 \pm 65$ & $207 \pm 44^{b}$ & $249 \pm 169$ & $296 \pm 192$ & $170 \pm 74^{b}$ & $91 \pm 14$ & $92 \pm 13$ & $90 \pm 15$ \\
\hline
\end{tabular}

$\mathrm{SRL}=$ sirolimus; $\mathrm{AZA}$ = azathioprine.

aP $<0.05$ for the comparison of mean cholesterol or triglyceride concentrations between day 0 and day 360 . bP $<0.05$ for cholesterol, triglyceride or glucose concentrations determined at individual study visits for patients receiving SRL vs AZA (unpaired Student $t$-test). 
$\mathrm{mg} /$ day $)$ to day $360(118.5 \pm 32.2 \mathrm{mg} /$ day $)$.

\section{Concentration-effect relationships}

Mean weight increased from $64.5 \pm 12.5$ $\mathrm{kg}$ pretransplant to $72.4 \pm 13.0 \mathrm{~kg}$ at day 360 , an increase of $12 \%$, with no significant differences comparing SRL and AZA patients. Mean pretransplant cholesterol (172 $\pm 49 \mathrm{mg} / \mathrm{dL})$ and triglyceride $(174 \pm 101 \mathrm{mg} /$ $\mathrm{dL}$ ) concentrations increased after transplantation, reaching maximum levels at day 60 $(260 \pm 71 \mathrm{mg} / \mathrm{dL})$ and $120(253 \pm 167 \mathrm{mg} /$ $\mathrm{dL}$ ), respectively (Table $3, \mathrm{P}<0.05$ ). Using a general linear model for repeated measures we observed that, at any given visit after transplantation, mean cholesterol and triglyceride concentrations were higher in patients receiving SRL compared to patients receiving AZA (Table 3, $\mathrm{P}<0.001$ ). However, there was no significant difference in the pattern or magnitude of increase in cholesterol and triglyceride concentrations during the study period, using visit and treatment group (SRL or AZA) in a two-way interaction model $(\mathrm{P}=0.25)$. There were no significant differences between mean pretransplant glucose concentrations and the concentration observed at day 360. Patients receiving SRL showed significantly higher pretransplant $(95 \pm 26$ vs $84 \pm 13 \mathrm{mg} / \mathrm{dL}, \mathrm{P}<$ $0.05)$ and day $180(99 \pm 20 v s 90 \pm 14 \mathrm{mg} / \mathrm{dL}$, $\mathrm{P}<0.05)$ mean glucose concentrations compared to patients receiving AZA.

We then divided cholesterol and triglyceride concentrations into quartiles and compared the proportion of measurements in each quartile according to treatment (AZA or SRL) and study visit (30, 90, 180, and 360 days). Patients receiving SRL showed a significantly higher proportion of cholesterol (Figure 1A) and triglyceride (Figure 1B) concentrations in the upper interquartile ranges. Also, the use of statin increased from 30 to 360 days and was significantly higher in patients receiving SRL compared to AZA (Figure 1C). In four patients (3 SRL, 1 AZA)

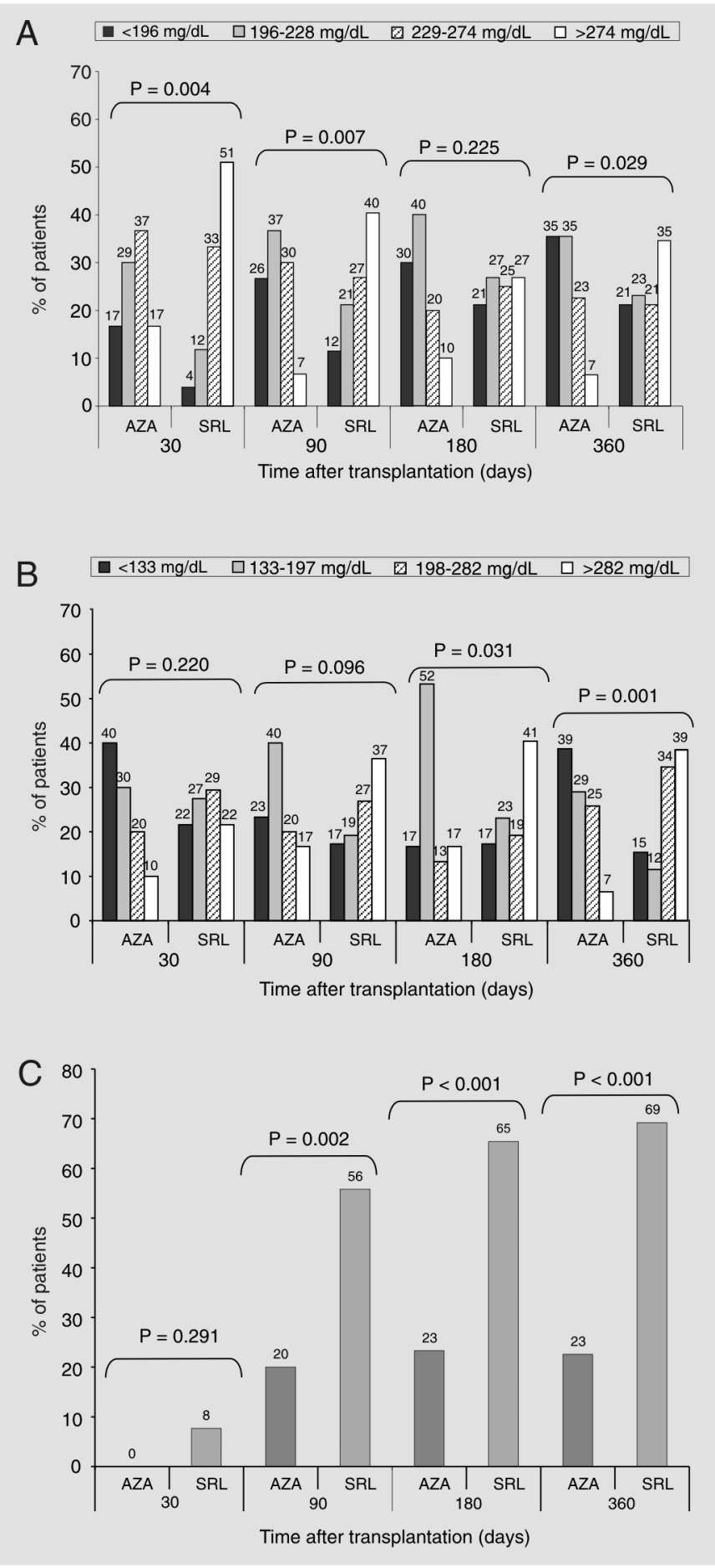

Figure 1. Comparison of the proportion of serum cholesterol $(A)$ and triglyceride (B) concentrations, according to interquartile ranges, in patients receiving azathioprine (AZA) or sirolimus (SRL). Unpaired independent Student $t$-test was used to determine statistical significance between mean in each study visit. $C$, Comparison of the proportion of patients in each group (AZA or $\mathrm{SRL}$ ) receiving statins. Exact chi-square test was used to determine statistical significance. 
statin treatment had to be discontinued due to adverse events, mainly muscle pain and elevated creatine-phosphokinase.

The correlations between CsA or SRL concentrations, PRED doses and cholesterol concentrations $\left(\mathrm{CsA}: \mathrm{r}^{2}=0.02, \mathrm{P}=0.002\right.$; SRL: $\mathrm{r}^{2}=0.0, \mathrm{P}=0.8$; PRED: $\mathrm{r}^{2}=0.026, \mathrm{P}<$ $0.001)$ or triglyceride $\left(\mathrm{CsA}: \mathrm{r}^{2}=0.0, \mathrm{P}=0.9\right.$; SRL: $\mathrm{r}^{2}=0.3, \mathrm{P}=0.005$; PRED: $\mathrm{r}^{2}=0.001$, $\mathrm{P}=0.5$ ) were poor. Using stepwise forward multivariate analysis, including CsA and SRL concentrations and PRED doses, the variable independently associated with cholesterol was CsA concentration $\left(\mathrm{r}^{2}=0.054, \mathrm{P}<\right.$ $0.001)$ and the variable independently associated with triglyceride concentrations was SRL concentration $\left(\mathrm{r}^{2}=0.03, \mathrm{P}=0.005\right)$.
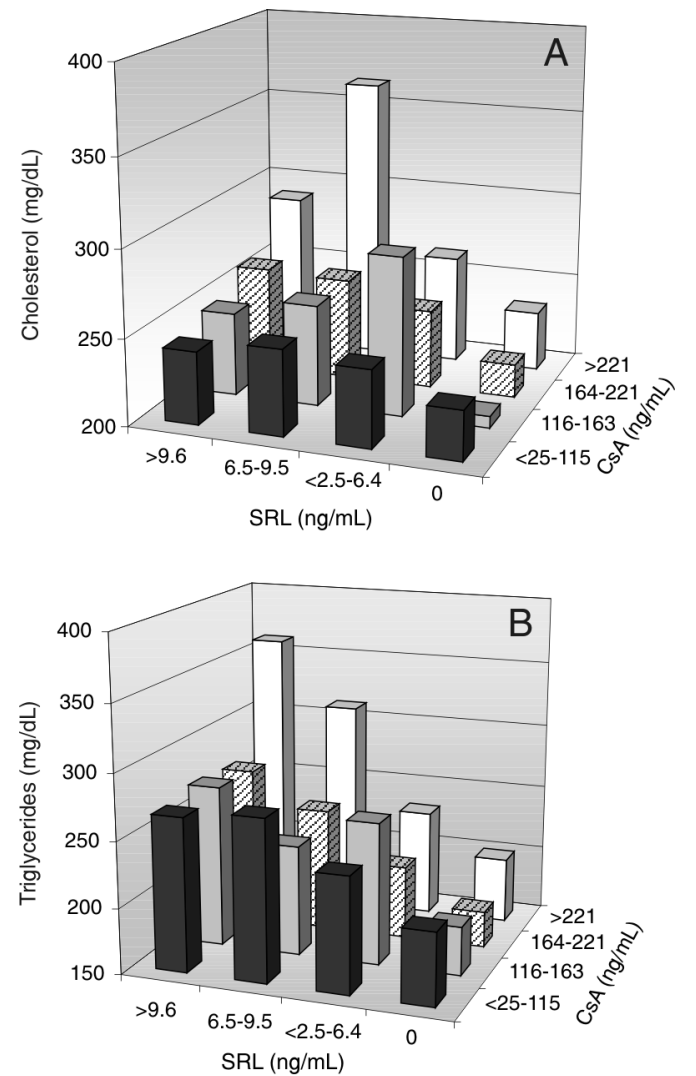

Figure 2. Combined effect of cyclosporin and sirolimus whole blood concentrations (according to interquartile ranges) on serum cholesterol $(A)$ and triglyceride (B) concentrations. $\mathrm{AZA}=$ azathioprine; $\mathrm{SRL}=$ sirolimus; $\mathrm{CsA}=$ cyclosporin A. Two-way analysis of variance was used to determine statistical significance.
Since linear correlations were not strong and PRED doses were not associated with either cholesterol or triglyceride concentrations, we then stratified CsA $(<25-115,116$ $163,164-221$, and $>221 \mathrm{ng} / \mathrm{mL})$ and SRL (0 (patients receiving AZA), 0.1-6.4, 6.5-9.5, and $>9.5 \mathrm{ng} / \mathrm{mL}$ ) concentrations into quartiles and searched for a combined effect of both drug concentrations on cholesterol and triglyceride concentrations using two-way analysis of variance. CsA $(\mathrm{P}<0.0001)$ and SRL $(\mathrm{P}<0.0001)$ interquartile ranges correlated with cholesterol concentrations and the combined effect of both drugs was also significantly associated with cholesterol concentrations $(\mathrm{P}=0.001$, Figure $2 \mathrm{~A})$. On the other hand, only SRL interquartile ranges showed a significant correlation with triglyceride concentrations $(\mathrm{P}<0.0001$, Figure $2 \mathrm{~B})$.

To better understand the relationship between pretransplant risk factors, drug exposure, and the pattern and magnitude of cholesterol and triglyceride increase and need of statins after transplantation we calculated for each patient $\mathrm{Cav}_{\mathrm{CsA}}, \mathrm{Cav}_{\mathrm{SRL}}, \mathrm{Cav}_{\mathrm{PRED}}$, $\mathrm{CAV}_{\mathrm{CHOL}}$, and $\mathrm{Cav}_{\mathrm{TG}}$ using the linear trapezoidal rule. Using linear regression analysis, age $\left(r^{2}=0.05, P=0.05\right)$, hypertension $\left(r^{2}\right.$ $=0.05, \mathrm{P}=0.04)$, pretransplant cholesterol concentration $\left(\mathrm{r}^{2}=0.23, \mathrm{P}<0.001\right)$, use of $\operatorname{SRL}\left(r^{2}=0.06, P=0.03\right)$, and use of statin $\left(r^{2}\right.$ $=0.2, \mathrm{P}<0.001)$ were significantly associated with $\mathrm{Cav}_{\mathrm{CHOL}}$. Similarly, age $\left(\mathrm{r}^{2}=0.08\right.$, $\mathrm{P}=0.01)$, hypertension $\left(\mathrm{r}^{2}=0.06, \mathrm{P}=0.04\right)$, pretransplant triglyceride concentrations $\left(\mathrm{r}^{2}\right.$ $=0.15, \mathrm{P}=0.001)$, use of SRL $\left(\mathrm{r}^{2}=0.09, \mathrm{P}\right.$ $=0.006), \operatorname{Cav}_{\mathrm{SRL}}\left(\mathrm{r}^{2}=0.07, \mathrm{P}<0.02\right)$, and use of statin $\left(\mathrm{r}^{2}=0.15, \mathrm{P}<0.001\right)$ were significantly associated with $\mathrm{Cav}_{\mathrm{TG}}$. Using multiple stepwise linear regression analysis, only age and pretransplant cholesterol concentration were independently and significantly associated with $\mathrm{Cav}_{\mathrm{CHOL}}\left(\mathrm{r}^{2}=0.34, \mathrm{P}\right.$ $<0.0001)$. Similarly, pretransplant triglyceride concentration was independently and significantly associated with $\mathrm{Cav}_{\mathrm{TG}}\left(\mathrm{r}^{2}=0.3\right.$, $\mathrm{P}<0.0001)$. 
The influence of demographic parameters and drug exposures on $\mathrm{Cav}_{\mathrm{CHOL}}$ and $\mathrm{Cav}_{\mathrm{TG}}$ is shown in Table 4. Age, hypertension, pretransplant cholesterol concentration, use of SRL, and need for statin were significantly associated with higher mean $\mathrm{Cav}_{\mathrm{CHOL}}$. Hypertension, BMI, pretransplant triglyceride concentration, use of SRL, and $\mathrm{Cav}_{\mathrm{SRL}}$ were significantly associated with higher $\mathrm{Cav}_{\mathrm{TG}}$. Finally, we used binary logistic regression analysis to identify risk factors associated with hypercholesterolemia $(>240$ $\mathrm{mg} / \mathrm{dL}$ ) or hypertriglyceridemia ( $>200 \mathrm{mg} /$ $\mathrm{dL})$. For hypercholesterolemia, there was a correlation with age $\left(\mathrm{r}^{2}=0.22, \mathrm{P}<0.007\right)$, pretransplant cholesterol concentration $\left(\mathrm{r}^{2}=\right.$ $0.36, \mathrm{P}=0.0001)$ and pretransplant triglyceride concentration $\left(\mathrm{r}^{2}=0.19, \mathrm{P}=0.02\right.$. $\mathrm{Cav}_{\mathrm{SRL}}\left(\mathrm{r}^{2}=0.1, \mathrm{P}=0.07\right)$ and $\operatorname{Cav}_{\mathrm{PRED}}\left(\mathrm{r}^{2}=\right.$ $0.11, \mathrm{P}=0.07$ ) were marginal. For hypertriglyceridemia, there was a correlation with pretransplant triglyceride concentration $\left(\mathrm{r}^{2}\right.$ $=0.29, \mathrm{P}=0.001)$ and $\mathrm{Cav}_{\mathrm{SRL}}\left(\mathrm{r}^{2}=0.15, \mathrm{P}=\right.$ $0.03)$, with age $\left(r^{2}=0.11, P=0.06\right)$ reaching marginal significance. In a multivariate binary logistic regression analysis, only pretransplant cholesterol concentration above $205 \mathrm{mg} / \mathrm{dL}$ was independently associated with development of hypercholesterolemia (relative risk, $\mathrm{RR}=20, \mathrm{CI} 3.8-104.6, \mathrm{P}=$ $0.0004)$ whereas pretransplant triglyceride concentration above $150 \mathrm{mg} / \mathrm{dL}(\mathrm{RR}=7.2$, CI 1.6-32.4, $\mathrm{P}=0.01)$ or above $211 \mathrm{mg} / \mathrm{dL}$ $(\mathrm{RR}=19.8, \mathrm{CI} 3.6-107.9, \mathrm{P}=0.0006)$ and use of SRL ( $R R=3$, CI 1.0-8.8, P = 0.0049) were independently associated with development of hypertriglyceridemia.

\section{Discussion}

As shown in Table 1, this transplant population can be considered to be at low risk to develop hyperlipidemia. Most patients are young, white, non-obese, and non-diabetic, with a relatively short period on dialysis and with normal pretransplant cholesterol and triglyceride concentrations (1). The high prevalence of males and hypertensive patients is typical of any transplant population but there were no significant differences between patients receiving SRL or AZA that might lead to the development of hyperlipidemia.

CsA doses and concentrations were lower in the SRL group than in the AZA group because of the synergistic pharmacokinetic/

Table 4. Mean cholesterol $\left(\mathrm{Cav}_{\mathrm{CHOL}}\right)$ and triglyceride $\left(\mathrm{Cav}_{\mathrm{TG}}\right)$ according to risk factors during the first 12 months after transplantation.

\begin{tabular}{|c|c|c|c|c|}
\hline \multirow{2}{*}{$\begin{array}{l}\text { Risk factor } \\
\text { Group (AZA/SRL) }\end{array}$} & \multicolumn{2}{|c|}{$\mathrm{Cav}_{\mathrm{CHOL}}(\mathrm{mg} / \mathrm{dL})$} & \multicolumn{2}{|c|}{$\mathrm{Cav}_{\mathrm{TG}}(\mathrm{mg} / \mathrm{dL})$} \\
\hline & $218 \pm 32$ & $253 \pm 52^{a}$ & $191 \pm 64$ & $267 \pm 13^{a}$ \\
\hline Age $(<36.5$ years $>)$ & $222 \pm 39$ & $258 \pm 51^{a}$ & $219 \pm 129$ & $259 \pm 108$ \\
\hline BMI $\left(<23.9, \mathrm{~kg} / \mathrm{m}^{2}>\right)$ & $234 \pm 45$ & $246 \pm 52$ & $209 \pm 71$ & $268 \pm 147^{b}$ \\
\hline Dialyses time (<15.5 months $>)$ & $238 \pm 46$ & $242 \pm 52$ & $231 \pm 130$ & $249 \pm 109$ \\
\hline Pretransplant cholesterol $(<166 \mathrm{mg} / \mathrm{dL}>)$ & $223 \pm 41$ & $260 \pm 50^{a}$ & $224 \pm 101$ & $258 \pm 137$ \\
\hline Pretransplant triglyceride $(<150 \mathrm{mg} / \mathrm{dL}>)$ & $231 \pm 41$ & $251 \pm 55$ & $200 \pm 98$ & $286 \pm 127^{a}$ \\
\hline Gender (male/female) & $234 \pm 48$ & $255 \pm 49$ & $240 \pm 108$ & $238 \pm 148$ \\
\hline Ethnicity (white/non-white) & $244 \pm 50$ & $234 \pm 47$ & $246 \pm 120$ & $229 \pm 120$ \\
\hline Rejection (yes/no) & $242 \pm 41$ & $240 \pm 50$ & $295 \pm 199$ & $234 \pm 108$ \\
\hline $\operatorname{Cav}_{\mathrm{CsA}}(<150 \mathrm{ng} / \mathrm{mL}>)$ & $247 \pm 54$ & $234 \pm 43$ & $254 \pm 117$ & $225 \pm 122$ \\
\hline $\operatorname{Cav}_{\mathrm{SRL}}(<5.5 \mathrm{ng} / \mathrm{mL}>)$ & $232 \pm 48$ & $248 \pm 48$ & $218 \pm 98$ & $262 \pm 137$ \\
\hline $\operatorname{Cav}_{\text {PRED }}(<11.7 \mathrm{mg} /$ day $>)$ & $246 \pm 50$ & $230 \pm 46$ & $246 \pm 131$ & $229 \pm 99$ \\
\hline Hypertension (yes/no) & $246 \pm 46$ & $209 \pm 53^{b}$ & $252 \pm 124$ & $175 \pm 65^{b}$ \\
\hline Statin (yes/no) & $260 \pm 51$ & $216 \pm 34^{a}$ & $282 \pm 139$ & $188 \pm 62^{a}$ \\
\hline
\end{tabular}

$\mathrm{AZA}=$ azathioprine $; \mathrm{SRL}=$ sirolimus; $\mathrm{BMI}=$ body mass index; $\mathrm{Cs} \mathrm{A}=$ cyclosporin $\mathrm{A} ; \mathrm{PRED}=$ prednisone . aP $<0.01$ and ${ }^{\mathrm{b} P}<0.05$ for $\mathrm{Cav}_{\mathrm{CHOL}}$ and $\mathrm{Cav}_{\mathrm{TG}}$ (unpaired independent Student $t$-test). 
pharmacodynamic interaction between CsA and SRL (15). Moreover, a fast taper of PRED was performed in the SRL group during the first 3 months, with the dose remaining unchanged after this period. Nevertheless, as previously demonstrated, there was an increase in cholesterol and triglyceride concentrations peaking between 60 and 90 days, with a subsequent reduction up to one year after transplantation (Table 3), compatible with reduction of drug dosages and specific treatment with statins (8).

Compared to patients receiving AZA, patients receiving SRL, although showing lower concentrations of CsA and a faster taper of PRED, had higher mean concentrations of cholesterol and triglycerides during the first year (Table 2). Except for higher mean values, there were no unusual patterns in the elevation of cholesterol and triglyceride levels since in a two-way (patient $v s$ visit) interaction model there were no significant differences between patients receiving SRL or AZA. This was further confirmed when we looked at the distribution of patients according to cholesterol or triglyceride concentration (Figure 1), which showed that a higher proportion of patients were above the 50 and $75 \%$ interquartile range in the SRL group compared to the AZA group. A large fraction of patients in the SRL group also received statins to reduce cholesterol and triglyceride concentrations but this strategy was not fully effective due to the magnitude of the increase and/or the relative potency of the statin used (18-20).

Knowing that patients receiving SRL displayed higher mean cholesterol and triglyceride concentrations we then searched for concentration-effect relationships. Since all patients were submitted to a similar CsA and PRED dose reduction and were receiving fixed doses of SRL, this was only possible due to the considerable inter- and intraindividual variability in both CsA and SRL concentrations (21). Using a linear model and considering patients receiving AZA to have
SRL concentrations equal to zero, we observed a significant and independent but weak correlation between individual CsA concentrations and posttransplant cholesterol concentrations $\left(\mathrm{r}^{2}=0.054, \mathrm{P}<0.001\right)$ and between SRL and triglyceride concentrations $\left(\mathrm{r}^{2}=0.03, \mathrm{P}=0.005\right)$. Prednisone doses did not show such correlations perhaps because all patients received comparable doses and underwent a similar dose reduction over the first year of transplantation. By dividing CsA and SRL concentration into interquartile ranges and comparing them with cholesterol or triglyceride concentration in a twoway interaction model we observed that while cholesterol concentration after transplant correlated with CsA and SRL concentration ranges $(\mathrm{P}=0.001$, Figure $2 \mathrm{~A})$, triglyceride concentration correlated exclusively with SRL concentrations $(\mathrm{P}<0.0001$, Figure $2 \mathrm{~B})$. This is in agreement with studies comparing CsA-based versus SRL-based immunosuppressive regimens $(22,23)$.

Perhaps more important than correlating individual drug concentrations or ranges, which changed over the first year according to a predefined protocol, with cholesterol or triglyceride concentrations after transplant, is to clearly identify risk factors in patients with persistent hyperlipidemia, with or without specific treatment, during the first year of transplantation. Individual one-year areas under the time-concentration curves were calculated for cholesterol and triglyceride as well as for CsA and SRL and PRED doses. Again, using multiple stepwise linear regression analysis, only age and pretransplant cholesterol concentration were independently and significantly associated with $\mathrm{Cav}_{\mathrm{CHOL}}\left(\mathrm{r}^{2}=0.34, \mathrm{P}<0.0001\right)$ and pretransplant triglyceride concentration was independently and significantly associated with $\mathrm{Cav}_{\mathrm{TG}}\left(\mathrm{r}^{2}=0.3, \mathrm{P}<0.0001\right)$.

By dividing the population according to demographic risk factors and drug exposure below or above median values we identified that age, hypertension, pretransplant choles- 
terol concentration, use of SRL, and need for statin were significantly associated with higher mean $\mathrm{Cav}_{\mathrm{CHOL}}$. Similarly, hypertension, BMI, pretransplant triglyceride concentration, use of SRL, and $\mathrm{Cav}_{\mathrm{SRL}}$ were significantly associated with higher $\mathrm{Cav}_{\mathrm{TG}}$. Finally, a binary forward multiple logistic regression analysis considering patients having persistent hyperlipidemia after transplantation $\left(\mathrm{Cav}_{\mathrm{CHOL}}>240 \mathrm{mg} / \mathrm{dL}\right.$ or $\mathrm{Cav}_{\mathrm{TG}}>200$ $\mathrm{mg} / \mathrm{dL}$ ) showed that only pretransplant cholesterol concentrations above $205 \mathrm{mg} / \mathrm{dL}$ were independently associated with the development of persistent hypercholesterolemia $(R R=20$, CI 3.8-104.6, P = 0.0004). On the other hand, pretransplant triglyceride concentrations above $150 \mathrm{mg} / \mathrm{dL}(\mathrm{RR}=7.2$, CI 1.6-32.4, $\mathrm{P}=0.01$ ) or above $211 \mathrm{mg} / \mathrm{dL}$ $(\mathrm{RR}=19.8, \mathrm{CI} 3.6-107.9, \mathrm{P}=0.0006)$ and use of SRL ( RR = 3, CI 1.0-8.8, P = 0.0049) were independently associated with development of persistent hypertriglyceridemia $(14,21,24,25)$.

The cellular and molecular mechanisms of the effects of SRL resulting in hyperlipi- demia are not completely known. There are initial data suggesting that the molecular target of rapamycin is involved in intracellular insulin signaling and lipid synthesis $(13,26,27)$. Furthermore, increased levels of apolipoprotein CIII, an inhibitor of lipoprotein lipase (28), and reduced catabolism of apolipoprotein B100-containing lipoproteins (29) may also be involved in the mechanisms responsible for hyperlipidemia in patients receiving SRL.

Overall, these data suggest that in patients receiving CsA-based immunosuppressive therapy with tightly controlled steroid dosage and taper, persistent hypercholesterolemia is more frequent among patients with higher pretransplant cholesterol concentrations and is dependent on both CsA and SRL concentrations. Hypertriglyceridemia is more frequent among patients with higher pretransplant triglyceride concentrations and is dependent on SRL concentrations. This information may help to select immunosuppressive drug regimens for kidney transplant candidates.

\section{References}

1. Donald EH (2000). Hyperlipidemia in renal transplant recipients. Graft, 3: 177-184.

2. Wissing KM, Daniel A, Nilufer B et al. (2000). Hypercholesterolemia is associated with increased kidney graft loss caused by chronic rejection in male patients with previous acute rejection. Transplantation, 70: 464-472.

3. Gokal R, Mann JI, Moore RA et al. (1979). Hyperlipidemia following renal transplantation. Quarterly Journal of Medicine, 48: 507-517.

4. Kasiske BL \& Umen AJ (1987). Persistent hyperlipidemia in renal transplant recipients. Medicine, 66: 309-316.

5. Vathsala A, Weinberg RB, Schoenberg $L$ et al. (1989). Lipid abnormalities in cyclosporin-prednisone-treated renal transplant recipients. Transplantation, 48: 37-43.

6. Kahan BD, for the Rapamune US Study Group (2000). Efficacy of sirolimus compared with azathioprine for reduction of acute renal allograft rejection: a randomised multicentre study. Lancet, 356: 194-202.

7. MacDonald AS, for the Rapamune Global Study Group (2001). A worldwide, phase III, randomized, controlled, safety and efficacy study of a sirolimus/cyclosporin regimen for prevention of acute rejection in recipients of primary mismatched renal allografts. Transplantation, 71: 271-280.
8. Shih-Chieh JC \& Kahan BD (2003). Dyslipidemia in renal transplant recipients treated with a sirolimus and cyclosporin-based immunosuppressive regimen: Incidence, risk factors, progression, and prognosis. Transplantation, 76: 375-382.

9. Kirk JK \& Dupuis RE (1995). Approaches to the treatment of hyperlipidemia in the solid-organ transplant recipient. Annals of Pharmacotherapy, 29: 879-891.

10. Chan MK, Varghese Z, Ppersaud JW et al. (1981). The role of multiple pharmacotherapy in the pathogenesis of hyperlipidemia after renal transplantation. Clinical Nephrology, 15: 309-313.

11. Derfler K, Hayde M \& Heinz G (1991). Decreased postheparin lipolytic activity in renal transplant recipients with cyclosporin. Kidney International, 40: 720-727.

12. Apanay DC, Neylan JF, Ragab MS et al. (1994). Cyclosporin increases the oxidizability of low-density lipoproteins in renal transplant recipients. Transplantation, 58: 663-669.

13. Morrisett JD, Chada AF, Hoogeveen R et al. (2002). Effects of sirolimus on plasma lipids, lipoprotein levels and fatty acid metabolism in renal transplant patients. Journal of Lipid Research, 43: 1170-1180.

14. Kahan BD \& Kramer WG (2001). Median effect analysis of efficacy versus adverse effects of immunosuppressants. Clinical Pharma- 
cology and Therapeutics, 70: 74-81.

15. Kahan BD, Knight R, Schoenberg L et al. (2003). Ten years of sirolimus therapy for human renal transplantation: The University of Texas at Houston experience. Transplantation Proceedings, 35: 25S-34S.

16. Kelly P \& Kahan BD (2002). Review: metabolism of immunosuppressant drugs. Current Drug Metabolism, 3: 275-287.

17. Di Marco GS, Andrade MCC, Felipe CR et al. (2003). Determination of sirolimus blood concentration using high-performance liquid chromatography with ultraviolet detection. Therapeutic Drug Monitoring, 25: 558-564.

18. Christians U, Jacobsen W \& Floren LC (1998). Metabolism and drug interactions of 3-hydroxy-3-methylglutaryl coenzyme A reductase inhibitors in transplant patients: are the statins mechanistically similar? Pharmacology Therapeutics, 80: 1-34.

19. Johnson RWG (2002). Sirolimus (Rapamune) in renal transplantation. Current Opinion in Nephrology and Hypertension, 11: 603-607.

20. Cosio FG, Todd EP, Ronald PP et al. (2002). Patient survival after renal transplantation III: The effects of statin. American Journal of Kidney Diseases, 40: 638-643.

21. Kahan BD, Napoli KL, Kelly PA et al. (2000). Therapeutic drug monitoring of sirolimus: correlations with efficacy and toxicity. Clinical Transplantation, 14: 97-109.

22. Kreis H, Cisterne JM, Land W et al. (2000). Sirolimus in association with mycophenolate mofetil induction for the prevention of acute graft rejection in renal allograft recipients. Transplantation, 69: 12521260.
23. Flechner SM, Goldfarb D, Modlin C et al. (2002). Kidney transplantation without calcineurin inhibitor drugs: A prospective, randomized trial of sirolimus versus cyclosporin. Transplantation, 74: 1070-1076.

24. Johnson RWG, Kreis H, Oberbauer R et al. (2001). Sirolimus allows early cyclosporin withdrawal in renal transplantation resulting in improved renal function and lower blood pressure. Transplantation, 72: 777-786.

25. Velosa JA, Timothy SL, Gloor JM et al. (2001). Cyclosporin elimination in the presence of TOR inhibitors: effects on renal function, acute rejection, and safety. American Journal of Kidney Diseases, 38: S3-S10.

26. Huffman TA, Isabelle MS \& John Jr CL (2002). Insulin-stimulated phosphorylation of lipin mediated by the mammalian target of rapamycin. Pharmacology, 99: 1047-1052.

27. Takano A, Usui I \& Haruta $T$ (2001). Mammalian target of rapamycin pathway regulates insulin signaling via subcellular redistribution of insulin receptor substrate 1 and integrates nutritional signals and metabolic signals of insulin. Molecular and Cellular Biology, 21: 5050-5062.

28. Tur MD, Garrigue V, Vela C et al. (2000). Apolipoprotein CIII is upregulated by anticalcineurins and rapamycin: Implications in transplantation-induced dyslipidemia. Transplantation Proceedings, 32 : 2783-2784.

29. Ron $\mathrm{CH}$, Ballantyne $\mathrm{CM}$, Pownall HJ et al. (2001). Effect of sirolimus on the metabolism of ApoB100-containing lipoproteins in renal transplant patients. Transplantation, 72: 1244-1250. 